\title{
From Nonprofit Organization to Social Enterprise - Case Study of Taiwan Lifeline International
}

\author{
Chun-Yu Wu Chang \\ Feng Chia University \\ E-mail address_ccy5353@yahoo.com.tw
}

\begin{abstract}
The purpose of this study aims to explore the possibilities of Taiwan Lifeline International turning into a social enterprise to remediate the burden of scarce resources. The European and American countries provide their people with good welfare through the support of government resources and policy. However, after several financial recessions, the financial shortfall makes the governments rethink their welfare policy. "Nonprofit organizations" therefore start to play an important role in providing various services to people in need. Governments of different countries constantly provide resources and assistance to nonprofit organizations over the years. By the case study of Taiwan Lifeline International, conclusions with profound insight and some possible solutions can be helpful to nonprofit organizations encountering similar challenges. This study investigates the history of nonprofit organizations in social enterprise. The second part of this study continues with the case study of Taiwan Lifeline International, which provides insights on the challenges and possible solutions of the transformation process from nonprofit organizations to social enterprise.

Keywords: profit organization, lifeline, social enterprise, cooperate social responsibility (CSR)
\end{abstract}

\section{INTRODUCTION}

This is an open access article under the CC-BY-NC license.

Social Enterprise Development

The need for financial stability urges nonprofit organizations to transform into social enterprises in order to achieve financial stability. During the progress, the importance of social enterprises also increases with time. (Defourny and Nyssens, 2010). A social enterprise is an enterprise indeed, which means it requires the ability of operation and management, risk tolerance, and resources seeking. Basically, it will have to operate sustainably on its own. Commercialization is necessary and inevitable (Boschee, 1998; Dees, 1998; Leadbeater, 1997; Austin et al., 2006; Perrini and Vurro, 2006).

The Development of Social Enterprises from Nonprofit Organizations in Taiwan

The origin of the transformation is the goal to help disadvantaged people to better blend into society and to solve their financial problems with innovative solutions ( $\mathrm{Wu}, 2012)$. At the same time, the transformation development in Taiwan is also in response to the needs of vulnerable populations. 
Partly because the needs keep growing with time and partly because there are more and more nonprofit organizations sharing the budgets, the issue of how to operate sustainably, which urges some of the nonprofit organizations to turn into social enterprises in order to maintain the service quality, is getting more attention. Challenges of the Transformation:

- Challenges in financial resources: there are only limited resources, which cannot support all nonprofit organizations (Acs et al., 1997; Qureshi and Herani, 2011).

- Challenges in human resources: a balance between financial sustainability and service quality is needed. (Eikenberry and Kluver, 2004).

- Challenges in the business model: An urge to solve operation and management problems results in transformations in nonprofit organization structures (Young, 2012).

- Challenges in organization positioning: Hybrid structures and organization goals may be a solution to positioning drift between profit and not-to-profit (Dees and Elias, 1998).

\section{LITERATURE REVIEW}

Common European Social Enterprise types include (1) cooperatives; (2) mutual aid societies; (3) associations/ voluntary organizations, and (4) foundations (Brandellero, 2004; Qiu, 2006).

On the other hand, common types of social enterprise organizations in Taiwan include (1) employment promotion groups, (2) community development groups, (3) service provision and product sales groups, and (4) independent venture philanthropy enterprises, and (5) social cooperatives (Guan, 2006b).

From the types of social enterprises, it is easy to understand the objectives for each of them. For example, service provision and product sales groups help people to provide services and/ or product sales, which may help develop a small business. On the other hand, employment promotion groups help people blend into society by means of getting back to the job market and to make a living. Community development groups aim to develop local communities through various activities, such as art and cultural events, tourism development and promotion, environment protection, and care for vulnerable populations.

From a Policy Perspective (Chinese Organizational Development Association, 2013; Lin, 2007; Li and Huang, 2007)

The United Kingdom sets up the "Big Society Capital." The "big society" is to create an environment that helps reduce unemployment problems. The "Big Society Capital" policy gathers public resources to help and support the development of social enterprises, and thus reducing obstacles during the process from a nonprofit organization to a social enterprise.

The United States has an open development policy, which is derived from bottom-up development and from the needs of the vulnerable populations through law-making and various approaches. In general, the purpose of the policy aims to solve the difficulty of social enterprise positioning.

As for Taiwan, the purpose of policy regarding social enterprise is to develop a legal system. The system should protect social enterprises and vulnerable populations. Such examples that have been implemented include:

- Diversified employment, which aims to solve the problem of social enterprise capacity and resource deficiency.

- Savings Mutual Empowerment-Volks Bank, which helps the vulnerable populations to increase saving, to improve personal skills, and to better blend into the society.

- Attracting venture capital with art and culture development, which enables the organization to move towards a self-sufficient business model with the help of venture capital investment. 
Yet there are some potential concerns regarding nonprofit organizations' transformation to social enterprise. For example, how to balance between nonprofit services and profit activities with limited human resources (Eikenberry and Kluver, 2004). Also, when there are more and more profitable activities, there may be a drift or positioning (Dees and Elias, 1998). These are important issues.

\section{RESEARCH METHODOLOGY}

This research started with the two following parts to investigate nonprofit organizations and from a nonprofit organization to social enterprise:

1. Case Study: case study was conducted on Taiwan Lifeline International to understand its organizational structure, financial status, and its transformation.

2. Literature exploration: Literature study provided an in-depth understanding of the nonprofit organization's transformation to social enterprises, the financial and human resource dilemmas encountered, and the social environment.

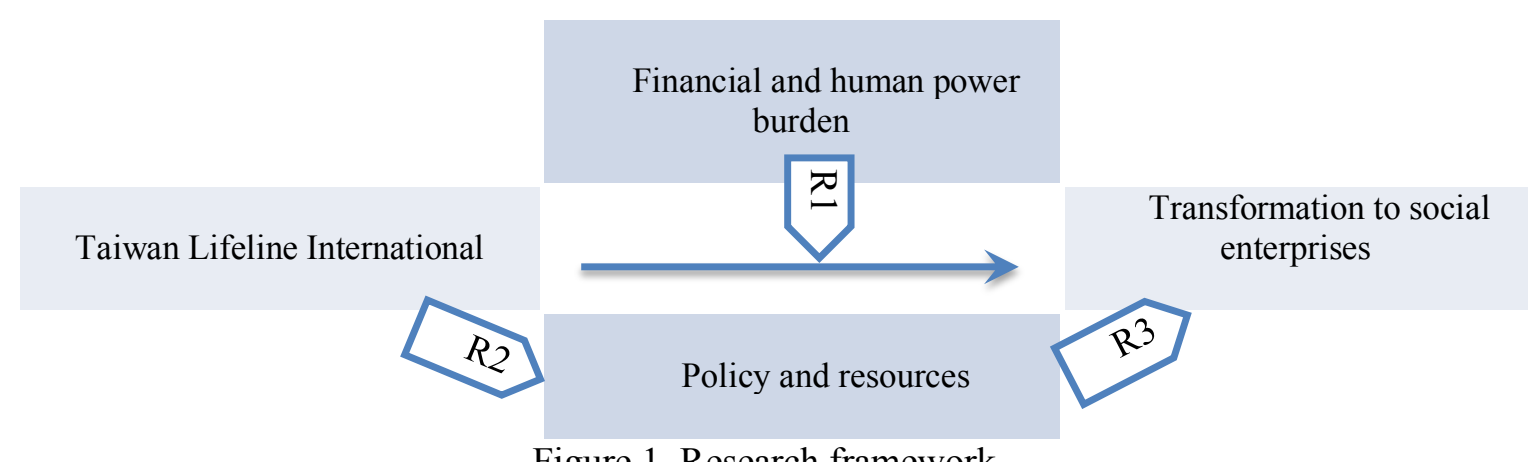

Figure 1. Research framework

Research propositions:

R1 : Influences of financial and human power burden from the change of social environment.

R2 : Transformation issues between nonprofit and profit positionings.

R3 : Combination of the government and public resources.

By studying the current status of Taiwan Lifeline International, the interactions with government policy directions and social resources, current financial and human difficulties, and the transformation of social enterprises, it can provide in-depth insight into the transformation of Taiwan Lifeline International.

PEST analysis on nonprofit organizations:

Table 1. PEST analysis of Taiwan Lifeline International.

\begin{tabular}{|c|c|}
\hline Political & Economic \\
\hline $\begin{array}{l}\text { Grants for nonprofit organizations become less } \\
\text { and more competitive as the policy changes with } \\
\text { time. }\end{array}$ & $\begin{array}{l}\text { The global financial burden makes it even harder } \\
\text { for nonprofit organizations to serve. }\end{array}$ \\
\hline Social & Technological \\
\hline $\begin{array}{l}\text { Average life increases, making the need for } \\
\text { nonprofit organization services to grow } \\
\text { significantly as well. }\end{array}$ & $\begin{array}{l}\text { The increase in technology usage, such as social } \\
\text { media, seems to bring up new problems for } \\
\text { people. }\end{array}$ \\
\hline
\end{tabular}




\title{
IV. FINDING AND DISCUSSION
}

\author{
Case Study -Taiwan Lifeline International
}

There are currently 23 Lifeline Associations in Taiwan now. However, due to the change of policy, the evolution of time, and the development of technology, Taiwan Lifeline International faces severe financial and human resource crisis. After serving for years, volunteers become aged, which makes night shifts of the phone service more and more challenging to them. Additionally, there are numerous nonprofit organizations in different areas nowadays, which makes it harder for Taiwan Lifeline International to recruit volunteers of the younger generation. For current volunteers, it is also challenging to learn to communicate with users through social media. The shortage of human resources and the soaring increase of user needs both reflect the challenges that Taiwan Lifeline International is facing right now. Even though a cloud system is built to remediate the deficiency of volunteers, the financial crisis still needs solutions. Efforts such as transformation to social enterprise, asking for donations from various organizations, working on government projects, and emphasizing creating shared values (CSV) were made to maintain good service quality and to operate sustainably.

In order to remediate the deficiency of human resources and budgets, Lifeline Associations hold various training and social service activities, such as art therapist development courses, family relationships reading groups, brainstorming workshops, Taiwan Lifeline International volunteer supervision training, Taiwan Lifeline International volunteer supervision on-the-job training, and corporate training (e.g., life education and career planning).

Through the years, there is some huge achievement of the Transformation of Taiwan Lifeline International to Social Enterprise, including the following. Taiwan Lifeline Associations are funded by government grants initially. Taiwan Lifeline Associations start to raise funds from enterprises as well as from the general public. They also work on various projects to gain more income. Also, by emphasizing corporate and public recognition, the creation of shared value (CSV) initiates some of the companies and people to make donations spontaneously or to join forces with Taiwan Lifeline International to serve vulnerable populations, which helps achieve mutual goals. Now all of the Taiwan Lifeline Associations are financially independent. Though the transformation process is moving forward slowly, the experience can be valuable for nonprofit organizations with similar resource burden.

\section{CONCLUSION AND FURTHER RESEARCH}

The core goal of Taiwan Lifeline International is to protect valuable lives, enhance suicide prevention, and contribute to society's stability. To fulfill such goals, Taiwan Lifeline International associations provide various services, including twenty-four-hour hotline phone services, counseling services, couple-counseling services, public workshops regarding suicide prevention, and cooperative training.

Further, about 800,000 people die due to suicide every year. The number of suicide attempts is more than twice the number of suicide deaths, which means suicide prevention is an important issue. The suicide rate in Taiwan is much higher than the standardized suicide mortality rate provided by the WTO. Therefore, this demonstrates that suicide prevention is indeed a challenging issue in Taiwan. 
With the increasing needs, Taiwan Lifeline Associations start working on a government project and helping companies organize activities (e.g., training). By doing so, Lifeline Associations are able to operate sustainably and provide quality service.

However, during the transformation of nonprofit organizations to social enterprises, there are some changes in the management and operation. Gaining financial resources through profit activities will occupy some working hours, human resources, and other resources, which are meant to provide nonprofit services (Dees and Elias, 1998). In order to maintain service quality and serve the ever-increasing subjects in need, nonprofit organizations may need to recruit more people and/or to adjust organization structure (Young, 2012). Finally, as a social enterprise, it needs to have a business model and a strategy that really works. Therefore, the management needs to be open in order to succeed in such transformation (Peng, and Liang, 2019; Ko and Liu, 2020). Further study of the changes in organizational structures and the prevention of positioning drift during the transformation from nonprofit organizations to social enterprises is crucial and valuable.

Such experiences are valuable to a nonprofit organization with burdens in resources. By keep working on the common good of nonprofit organizations and partners (enterprises and the public), there will always be opportunities for a better tomorrow.

\section{REFERENCES}

Acs, Z., Morck, R., Shaver, J. M., and Yeung, B. (1997). The internationalization of small and medium-sized enterprises: A policy perspective. Small Business Economics, 9, 7-20.

Austin, J., Stevenson, H., and Wei-Skillern, J. (2006). Social and commercial entrepreneurship: Same, different, or both? Entrepreneurship Theory and Practice, 30(1), 1-23.

Boschee, J. (1998) Merging mission and money: A board member's guide to social

entrepreneurship: http://www.socialent.org/pdfs/MergingMission.pdf.

Brandellero, S. (2004). Social enterprise. Enterprise and innovation in deprived urban areas sharing the European experience. U.K.: Greater London enterprise.

Chinese Organizational Development Association (2013). Study of Taiwan Nonprofit Organization to Social Enterprise. Taipei: National Development Council.

Dees, J., G (1998). Enterprising Nonprofits. Harvard Business Review, 76(1), 54-67.

Dees, J.G., and Elias, Jann (1998). The challenges of combing social and commercial enterprise. Business Ethics Quarterly,8(1),174-175.

Defourny, J. (2001). Introduction: From the third sector to social enterprise. In C. Borzaga \& J. Defourny (Eds.), The emergence of social enterprise. London, England: Routledge, pp. 1-28.

Eikenberry, A. M., and Kluver, J. D. (2004). The marketization of the nonprofit sector: Civil society at risk? Public Administration Review, 64(2), 132-140.

Defourny, J., and Nyssens, M. (2010). Conceptions of Social Enterprise and Social Entrepreneurship in Europe and the United States: Convergences and Divergences. Journal of Social Entrepreneurship, 1(1), 32-53.

Guan, Y. (2006a). Management of Social Enterprises Organizations in Taiwan: Take the Sunshine Social Welfare Foundation as an example. Published in 2006 Cross-Strait Non-Government Organizations Academic Forum and Practical Exchange Seminar, National Chengchi University Third Sector Research Center, Taipei.

Guan, Y. (2006b). Development of Social Enterprises in Taiwan. Presented at Hong Kong Social Enterprise Symposium, Central Policy Unit, and the Commission on Poverty, The Government of Hong Kong Special Administrative Region, Hong Kong. 
Ko, W.W., and Liu, G. (2020). The Transformation from Traditional Nonprofit Organizations to Social Enterprises: An Institutional Entrepreneurship Perspective. J Bus Ethics. Available at: https://doi.org/10.1007/s10551-020-04446-z

Lin, Y. (2007). Research on the Development of Social Enterprises in the U.K., and Proposals for Promoting Social Enterprise Employment Promotion Policy Planning. The Vocational Training Council of the Labor Commission of the Executive Yuan commissioned a research project.

Li, Z., and Huang, S. (2007). Social Enterprise Policy in the UK, Spain, and Hong Kong. Hong Kong: Information Research and Library Services Department, Hong Kong Legislative Council Secretariat, and Library Services.

Peng, X., Liang, C. (2019). Before Nonprofit Organisations Become Social Enterprises. Voluntas 30, 460-474.

$\mathrm{Wu}$, J. (2012). Social enterprise and social inclusion: Study of vulnerable women, National Chi Nan University.

Young, D. R. (2012). The State of Theory and Research on Social Enterprises. In B. Gidron \& Y. Hasenfeld (Eds.), Social Enterprises: An Organizational Perspective (19-46). NY: Palgrave Macmillan. 